\title{
HOW TO MANAGE XEROSTOMIA IN PROSTHODONTICS???
}

\author{
Dr. Opinder Pal Singh ${ }^{1}$ Dr. Rubina ${ }^{2}$ Dr. Nikita ${ }^{3}$ Dr. Neeraj Mittal ${ }^{4}$ Dr. Rishi Saini ${ }^{5}$ \\ ${ }^{1}$ PG Student Department of Prosthodontics and Crown \& Bridge Bhojia Dental College, Distt. Solan, Himachal Pradesh (India) \\ ${ }^{2}$ Private Practitioner (India) \\ ${ }^{3}$ PG Student Department of Prosthodontics and Crown \& Bridge Bhojia Dental College, Distt. Solan, Himachal Pradesh (India) \\ ${ }^{4}$ Senior Lecturer Department of Prosthodontics and Crown \& Bridge Jan Nayak Chaudhari Devi Lal Dental College, Haryana (India) \\ ${ }^{5}$ PG Student Department of Prosthodontics, Genesis Dental College, Ferozepur, Punjab (India) \\ Corresponding Author: \\ ${ }^{1}$ Mobile: 919814348999 Email: opinderbhalla@gmail.com
}

\begin{tabular}{|l|}
\hline Received : \\
$3^{\text {rd }}$ July, 2013 \\
Accepted: \\
$18^{\text {th }}$ Sept, 2013 \\
Available online: \\
$28^{\text {th }}$ Dec, 2013
\end{tabular}

\section{INTRODUCTION}

Xerostomia is a common symptom among middle aged and older adults. This apparent age-related trend is thought to represent the influence of medical conditions and their treatment rather than an age effect per se. ${ }^{1}$

Subjective dry mouth sensation is known as xerostomia, though when sialometry objectively demonstrates asaliva flow rate of under 0.1-0.2 $\mathrm{ml} / \mathrm{min}$ (resting whole saliva) and under $0.7 \mathrm{ml} / \mathrm{min}$ (stimulated whole saliva), the term sialopenia or salivary hyposecretion is used. This condition is equivalent to the secretion of less than $500 \mathrm{ml}$ of saliva a day. ${ }^{2}$

The prevalence of xerostomia is high among the general population, and increases with age - affecting approximately $30 \%$ of all individuals over age 65 years. $^{2}$

Saliva plays an important role in the functioning of full dentures as prosthesis does not rest barely on mucous membranes but on an interposed salivary film also. The retention of the complete upper denture and in a lesser degree of the lower, is also dependent on the salivary layer between the denture base and the oral tissues. Xerostomia can make wearing complete dentures difficult for the edentulous patient as it not only affects retention but also makes the oral mucosa more prone to injury.

\section{REVIEW OF LITERATURE}

Zora Blahova and Milan Neuman $\left(\mathbf{1 9 7 1}^{3}\right.$ wrote that viscosity of saliva helps prevent the dislodgment of denture, especially in the initial phase and so it becomes an important factor in retention.

Roy Y. Nakamoto $(\mathbf{1 9 7 9})^{4}$ described the use of a saliva substitute in postradiation xerostomia.

R. E. Lindstrom, J. Pawelchak et al (1979) ${ }^{5}$ wrote that retention fails at the moment the cohesive forces in the saliva or other substances are overcome.

Thomas J. Vergo and Sidney P. Kadish $(1981)^{6}$ designed a pilot study to test the feasibility of the reservoir denture, a complete removable denture prosthesis containing a reservoir chamber to hold and distribute artificial saliva in the irradiated edentulous patient with xerostomia.

Joseph A. Toljanic and Terry G. Zucuskie (1984) ${ }^{7}$ described the use of a palatal reservoir in denture patients with xerostomia. 
Mira Edgerton (1987) ${ }^{\mathbf{8}}$ described the use of a saliva as a significant factor in removable prosthodontic treatment. He wrote that the artificial saliva currently available on the market is based on carboxymethylcellulose, xylitol or mineral salts and have provided only short acting relief. Preliminary results with artificial saliva based on animal mucin have shown improved lubricating properties.

M.M. Ferguson and M.J. Barker (1994) ${ }^{9}$ described the use of saliva substitutes in the management of salivary gland dysfunction.

Gary F. Sinclair, Peter M. Frost et al (1996) ${ }^{\mathbf{1 0}}$ gave a new design for an artificial saliva reservoir for the mandibular complete denture.

Ana M. Diaz-Arnold and Cindy A. Marek (2002) ${ }^{11}$ wrote that in the partially or fully edentulous patient, susceptibility to mucosal ulcerations and fungal infections may increase because of decreased salivary flow. Patients should minimize denture use at times when decreased salivary flow is noted. Dentures must be soaked in water overnight. The oral mucosa and intaglio surface of aprosthesis can be sprayed throughout the day with artificial saliva.

Mark S. Chambers et al (2008) ${ }^{\mathbf{1 2}}$ wrote that irradiation of the major salivary glands induces changes in the volume, viscosity, $\mathrm{pH}$, and organic and inorganic constituents of whole saliva, including nonglandular components such as nonspecific debris (food residues), desquamated epithelial cells and microorganisms. Deterioration of the salivary function leads to a loss in taste acuity, reduction of whole saliva volume and increase in viscosity can impede prosthetic rehabilitation efforts and difficulty with deglutition can impair the patient's appetite, leading to weight loss and immune suppression.

AR Mendoza and MJ Tomlinson (2009) ${ }^{13}$ described a new technique for artificial saliva reservoirs in mandibular dentures.

\section{NORMAL SALIVARY FLOW RATES}

Daily secretion of saliva normally ranges between 800 and 1500 milliliters. Under basal awake conditions, about 0.5 milliliter of saliva, almost entirely of the mucous type, is secreted each minute. ${ }^{14}$
Salivary flow rates vary considerably during any one 24-hour period depending on the demand or the current physiologic status of the patient ${ }^{15}$. The unstimulated flow rate is $0.3 \mathrm{~mL} / \mathrm{min}$, whereas the flow rate during sleep is $0.1 \mathrm{~mL} / \mathrm{min}$; during eating or chewing, it increases to 4.0 to $5.0 \mathrm{~mL} / \mathrm{min}^{16}$. Any unstimulated flow rate below $0.1 \mathrm{~mL} / \mathrm{min}$ is considered hypofunction. Stimulated flow rate is, at maximum, $7 \mathrm{~mL} / \mathrm{min}$. Stimulated saliva is reported to contribute as much as $80 \%$ to $90 \%$ of the average daily salivary production. ${ }^{17}$

\section{CONDITIONS CAUSING XEROSTOMIA:}

Following conditions lead to xerostomia ${ }^{17}$

1. Chronic inflammatory disorders like Sjogren's syndrome, Rheumatoid arthritis, Systemic lupus erythematosus and Systemic sclerosis.

2. Genetic disorders like Autoimmune thyroiditis, Cystic fibrosis, Sphingolipid storage disease, Gaucher's disease, Thalassemia major and Systemic amyloidosis.

3. Metabolic disorders like Primary biliary cirrhosis, Sarcoidosis and Diabetes mellitus.

4. Viruses like HIV, Herpes viruses and Hepatitis C.

5. Other causes like end stage renal disease, medications, dehydration, eating disorders (anorexia / bulimia) and nutritional deficiencies.

\section{DRUGS CAUSING XEROSTOMIA}

Cytotoxic drugs, Drugs with anticholinergic effects like atropine and antimuscarinics, Tricyclic antidepressants, Serotonin reuptake inhibitors, Antihistamines, Antiemetics and Antipsychotics, Drugs with sympathomimetic actions like decongestants, bronchodilators, appetite suppressants, amphetamines, other drugs like lithium, omeprazole, oxybutynin, disopyramide, didanosine, diuretics and protease inhibitors lead to diminished salivary flow. ${ }^{17}$

\section{SIGNS AND SYMPTOMS OF XEROSTOMIA}

Xerostomia, which can differ in degree of severity from one individual to another, may present itself with one or more of the following symptoms difficulty in swallowing and speech, burning tongue, stomatitis, halitosis, difficulty in wearing dentures, sleep interruptions due to thirst, increased dental caries, salivary gland enlargement, angular cheilitis, oral candidiasis, papillary atrophy, opaque or viscous saliva, dessication or glossy appearance of oral mucosa, food debris or sloughed epithelium in the 
vestibule and audible clicking of oral soft tissues during speech. ${ }^{17}$

\section{MANAGEMENT OF XEROSTOMIA SYMPTOMATIC TREATMENT}

Sugar-free gum or candies may help to increase salivary output, but they may be inconvenient and affect patients' compliance. Chewing gums enhance salivary flow rates, but these actions are transient and the wearers of full dentures may be unable to use them. Frequent ingestion of sugar-free liquids may help. Water is the most important treatment for symptoms of dry mouth. The geriatric population is more susceptible to dehydration and should be reminded to drink water on a regular basis. Sipping water throughout the day keeps the oral mucosa hydrated and clears debris from the mouth. Sipping water during meals aids in chewing, swallowing and taste perception. Caffeine-containing beverages should be avoided. Using a room humidifier increases environmental humidity and may improve patient's oral comfort. ${ }^{18}$

\section{SYSTEMIC THERAPY}

Symptomatic relief for xerostomia can sometimes be obtained by treatment with parasympathomimetics such as pilocarpine hydrochloride or neostigmine bromide. Once the glandular activity has been stimulated in this way, the secretions may be improved even after withdrawal of the drug. They stimulate water \& electrolyte flow but require residual functional salivary gland tissue. The optimal dosage of pilocarpine is $5 \mathrm{mg}$ four times daily or 10 $\mathrm{mg}$ three times daily for at least eight to twelve weeks. Typical adverse effects are sweating, headache, nausea, mild abdominal pain, gastrointestinal upset, urinary frequency, chills, influenza-like symptoms, flushing, increased lacrimation and palpitations. Cevimeline reduces the symptoms of xerostomia in patients with Sjogren's Syndrome. Therapy with cevimeline, $30 \mathrm{mg}$ three times daily is well tolerated and provides substantive relief of xerostomia symptoms. Carbacholine may be of benefit in the treatment of radiation induced xerostomia. Pyridostigmine may be of benefit in the treatment of drug-related xerostomia. Bromhexine (32-48 mg daily) may also increase salivary flow. ${ }^{18}$

\section{ARTIFICIAL SALIVA \& SALIVARY SUBSTITUTES}

A number of patients with severe salivary gland dysfunction have inadequate functional tissue to respond adequately to sialogogues and for this group there is no alternative other than salivary substitute.

Artificial saliva acts by humidifying and lubricating the dehydrated oral mucosa. Likewise, it protects the oral cavity against irritation and facilitates mechanical functions like speech and swallowing. Saliva substitutes mainly consist of aqueous solutions containing the same mineral salts as those found in human saliva. As such, they mimic the natural functions of these elements in the oral cavity. Salts such as phosphates and calcium ions in particular exert a key buffering effect to normalize the oral $\mathrm{pH}$ and avoid chemical dissolution of the dental enamel, while restoring the demineralization/ remineralization balance of the teeth. ${ }^{18}$

Artificial saliva also usually contains enzymes with antimicrobial action or mucins as lubricants. Saliva substitutes must be placed in the mouth by sucking, dripping, or spraying saliva from a container carried in a pocket or purse. ${ }^{18}$

In an attempt to provide the necessary lubrication, various solutions containing glycerol have been compounded over the past century for lubricating and moisturising the mucosa over a longer period than does water alone. In some preparations, lemon juice or citric acid was also added to stimulate residual salivation but this is perhaps no longer appropriate as salivary substitutes are best reserved for those who cannot respond to gustatory stimulation. In addition, repeated application of citric acid could further damage the already compromised dentition due to low $\mathrm{pH}$ and its chelating action. Fermentation of glycerol by oral bacteria is another potential difficulty, with the local production of acids. As an extension of glycerol solutions, a pastille was developed consisting of glycerol, gelatin, sucrose, lemon essence, amaranth and citric acid but such pastilles are not well coped with as they require a certain amount of moisture already to be present in order to dissolve. Over the ensuing decade, more bland rinses were evaluated containing saline, sodium bicarbonate or magnesium hydroxide. The rationale of including an antacid was to raise plaque $\mathrm{pH}^{9}$ 
These appeared to assist in debridement of the mouth, similarly to water, and purportedly relieving tenderness but again did not provide any significant lasting effect for severe cases of xerostomia. A dilute, aqueous solution of chlorhexidine has also been recommended for its bacteriostatic effect in an attempt to parallel the antimicrobial functions of saliva, although this is a relatively non-specific approach. With the intention of producing a viscous preparation, Matzker and Schreiber incorporated sodium carboxymethyl cellulose in a phosphatebuffered saline solution along with calcium and phosphate to limit enamel demineralisation. Delivery of saliva substitutes can be done in bottles and canisters (sprays, gels and tubes), Denture reservoirs, Pastilles and Infusion pumps. ${ }^{9}$

Artificial saliva is divided into 2 groups: Carboxymethycellulose (CMC) based and Mucin based. $\mathrm{CMC}$ is used to impart lubrication and viscosity. Salts are added to mimic the electrolyte content of saliva. Calcium, Phosphate, Fluoride ions are added to provide remineralization potential. Mucin is derived from porcine gastric tissues or bovine submaxillary glands. Mucin based salivary substitutes are known to have the lowest contact angle and the best wetting properties on the denture base and the oral mucosa. Their rheological properties are more comparable to that of natural saliva (Table $1 \& 2$ ). ${ }^{9}$

Table 1-Formulation of Carboxymethylcellulose Saliva Substitute

\begin{tabular}{|l|l|}
\hline Sodium carboxymethylcellulose & $10.00 \mathrm{~g}$ \\
\hline Potassium chloride & $0.62 \mathrm{~g}$ \\
\hline Sodium chloride & $0.87 \mathrm{~g}$ \\
\hline Magnesium chloride & $0.06 \mathrm{~g}$ \\
\hline Calcium chloride & $0.17 \mathrm{~g}$ \\
\hline Di-potassium hydrogen orthophosphate & $0.80 \mathrm{~g}$ \\
\hline Potassium di-hydrogen orthophosphate & $0.30 \mathrm{~g}$ \\
\hline Sodium fluoride & $0.0044 \mathrm{~g}$ \\
\hline Sorbitol & $29.95 \mathrm{~g}$ \\
\hline Compound tartrazine solution & $0.1 \mathrm{ml}$ \\
\hline Methyl p-hydroxybenzoate & $1.00 \mathrm{~g}$ \\
\hline Spirit of lemon & $5.0 \mathrm{ml}$ \\
\hline Water to make total of & 1 litre \\
\hline
\end{tabular}

Table 2- Composition of Mucin Based Saliva

\begin{tabular}{|l|l|}
\hline Mucin & $35.00 \mathrm{~g}$ \\
\hline Potassium chloride & $1.20 \mathrm{~g}$ \\
\hline Sodium chloride & $0.85 \mathrm{~g}$ \\
\hline Di-potassium hydrogen orthophosphate & $0.35 \mathrm{~g}$ \\
\hline Magnesium chloride & $0.05 \mathrm{~g}$ \\
\hline Calcium chloride & $0.20 \mathrm{~g}$ \\
\hline Xylitol & $20.00 \mathrm{~g}$ \\
\hline Water to make total of & 1 litre \\
\hline
\end{tabular}

\section{PROSTHODONTIC MANAGEMENT OF XEROSTOMIA PATIENTS}

\section{The Role of Saliva in Denture Retention}

Saliva allows for the formation of a vacuum pressure on the seating of dentures and contributes significantly to denture retention and satisfaction with the removable prosthesis. In the denture wearing population, salivary wetting mechanics are necessary to create adhesion, cohesion and surface tension that ultimately lead to increased retention of prostheses. Adhesion is the bond created by saliva between the oral mucosal epithelium and denture base. Cohesion is the bonding between saliva components that leads to greater retention of prostheses. Surface tension is the denture's ability to resist separation from tissues and is related closely to the fit of the prosthesis. An intimate fit of denture bases to supporting tissues and the presence of adequate border seals will provide optimal denture function, provided that saliva is adequate in amount, flow and consistency. Adhesion, cohesion and surface tension are interrelated and they all depend on saliva. Saliva is also necessary to prepare food for digestion and deglutition; its insufficient output adversely affects nutrition in the elderly edentulous population. Lack of saliva in the denture mucosa interface can produce denture sores owing to lack of lubrication and prosthesis retention, as well as to a reduction in the number of immune factors that the salivary film provides. Lack of denture stability and retention can cause social embarrassment if prostheses dislodge during common functions; they ultimately could impair a person's ability or willingness to speak or eat, particularly in public. Therefore salivary hypofunction can have a devastating effect for the denture-wearing edentulous patient because of numerous compounding factors that affect chewing, swallowing, taste and speech. ${ }^{19}$

\section{DRY MOUTH AND DENTURES}

Patients with salivary hypofunction are more susceptible to mucosal candidiasis, which can manifest as pseudomembranous covering or erythema of the underlying tissues and a burning sensation of the tongue or other intraoral soft tissues. In the 
patient with insufficient saliva, the lack of salivary lubrication can produce traumatic ulcerations of the mucosa. The ulcerations manifest as small, painful lesions with elevated circumferential fibrous tissue. In patients who wear dentures, if the cause of the ulceration is not treated, a frictional reactive hyperplasia can occur that develops into an epulis fissuratum. Although there is insufficient scientific evidence regarding the use of denture adhesives in general, their use to enhance retention of well made prosthesis is acceptable and, at times, necessary. Moistened denture adhesives improve adhesion and cohesion and create a uniform fill of material, particularly on well-made prostheses, that improves surface tension. Therefore, the use of adhesives in patients who have hyposalivation can lead to enhanced denture function and patient comfort. The patient should be educated regarding the daily use of adhesives and should be advised to visit the dentist annually to evaluate the adequacy of the prosthesis and the health of the underlying denture-bearing tissues. Idiopathic dysesthesia or stomatopyrosis (commonly called "burning mouth syndrome") is diagnosed in patients with xerostomia who wear dentures by means of excluding fungal, traumatic, mucosal, neoplastic, endocrine, serologic or nutritional causes. It is characterized by a burning sensation in one or several oral structures in contact with the dentures. These patients' oral mucosa have a normal clinical appearance; the cause may be that microfriction of the denture against the mucosa induces a dysesthesia. ${ }^{19}$

\section{TREATMENT OF DRY MOUTH PROBLEMS IN DENTURE WEARERS}

Initial therapy begins with a thorough assessment of the underlying cause. In elderly patients, assessment must include a review of concurrent medical problems and medications. In the denture-wearing patient, the assessment must include the denture and the denture-bearing mucosal surface. If the dentist can see denture sores, he or she should consider that a poor denture fit may be a causative factor in the patient's salivary hypofunction and must treat it. This typically is the case for overextended mandibular lingual flanges. Excessive pressure in the lingual anterior regions potentially can cause mucosal soreness as well as hypofunction of the sublingual and submandibular glands and it requires adjustments to the prosthesis. ${ }^{19}$
Patients should be instructed to wet their prostheses before applying adhesive and a combined use of artificial saliva and denture adhesive appears to be beneficial. Salivary substitutes, artificial saliva and salivary stimulants can be beneficial for the denturewearing patient in terms prosthesis retention. During mealtime, greater intake of water is recommended. Although the use of adhesives in patients with hyposalivation requires additional care, it often is necessary to stabilize a removable prosthesis. ${ }^{19}$

\section{SALIVARY RESERVOIRS IN DENTURES}

To provide easier application of artificial saliva, an intraoral saliva reservoir in the hollowed lingual flange of a mandibular denture and palatal reservoir are also the techniques of choice. These reservoirs help the patient control his xerostomia with the help of salivary substitutes placed in them. Their results were poor because adequate cleansing of the denture was difficult, which prevented flow of the saliva substitute into the mouth. ${ }^{6,713}$

\section{PROCEDURE FOR SPLIT DENTURE}

Clinically, primary and secondary impressions were made in the normal manner. In the laboratory, a duplicate of the secondary models was then made. The duplicate models were then marked "Number 2 models". The maxillomandibular relationship was recorded with the mandible in retruded position and an acceptable freeway space. The models were then articulated in the normal way and the teeth set up for try in. Shorter teeth were used in the lower rim to allow a deeper area for future placement of reservoirs. The wax dentures were then tried in clinically. Using "Number 2 models" created after the secondary impression, and the wax dentures, a second articulator is set up with identical maxillomandibular relationships. ${ }^{13}$

Construction of the clear acrylic mandibular base: - The height of the clear acrylic base section first had to be determined. This was done by measuring the anterior height of the mandibular denture. Then the height of the lower anterior teeth was measured and $3 \mathrm{~mm}$ added on to allow for sufficient acrylic under the teeth for strength (Figure 1). The original wax dentures were then set aside and a new mandibular wax base was constructed, on the original articulator, to this base height. Five studd-buttons are positioned in the wax. These are placed exactly in the centre of the wax base and waxed in such a way that only the studd were above the wax. The rim was then waxed down to the model and flasked in the normal manner. Because accuracy was critical, vacuum mixed, hard 
stone was used. Once the wax was boiled out, separating medium was applied, the flask was packed with clear, denture acrylic. This was heat processed as per manufacturer's instructions. After processing, the clear acrylic base was deflasked. Care was taken in polishing to ensure that the square, occlusal edges were maintained (Figure. 2). ${ }^{13}$

\section{Construction of the upper mandibular section} Using the second articulator with the 'Number 2 models', the wax upper denture was placed on the upper model and the clear acrylic base placed on the lower model (Figure 3). To allow the upper section of the mandibular denture to be processed separately, it was waxed up on a duplicate of the clear acrylic base. This duplicate was formed by making an impression of its occlusal surface in a stock tray and pouring it up in die stone (Figure 4). In order to articulate this stone duplicate in the corresponding position to the clear acrylic base, a wax squash bite was made on the articulator, between the upper wax denture and the clear acrylic base (Figure 5). The clear acrylic base was then removed and the stone duplicate placed in its position. This was then plastered into place (Figure 6). The teeth were arranged and waxed into position in the normal manner (Figure 7). The dentures were then flasked and processed in pink acrylic. After deflasking, the upper segment of the mandibular denture was attached to the lower segment for polishing (Figure 8). The two sections should 'click' into place at this point. Polishing was done with the segments together to ensure a flush, smooth finish and no damage to the edges. The result was a full lower denture with a clear acrylic base and a removable, pink acrylic upper section (Figure 9). ${ }^{13}$

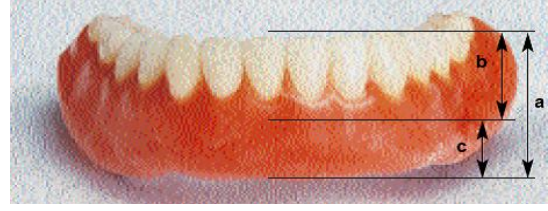

Figure 1: Determination of height of acrylic base

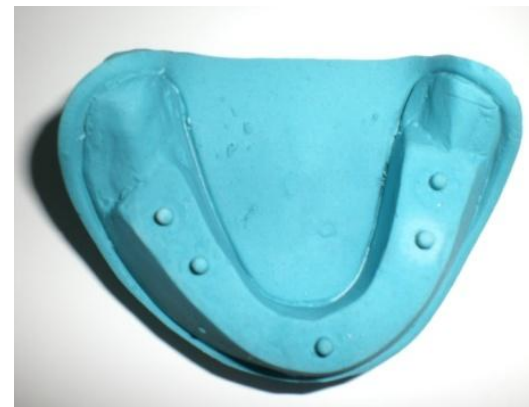

Figure 4: Duplicate of clear acrylic base formed in die stone

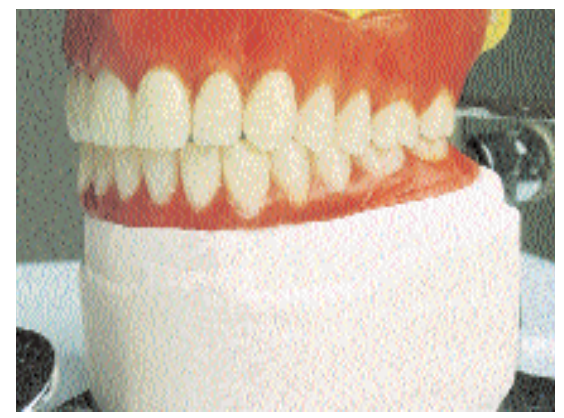

Figure 7: Teeth arrangement and wax up done,

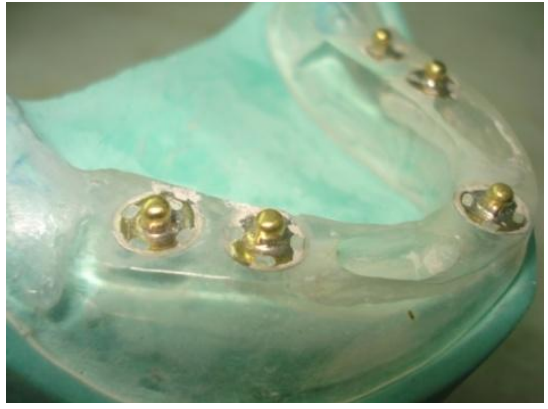

Figure 2: Processed clear acrylic base with studd buttons

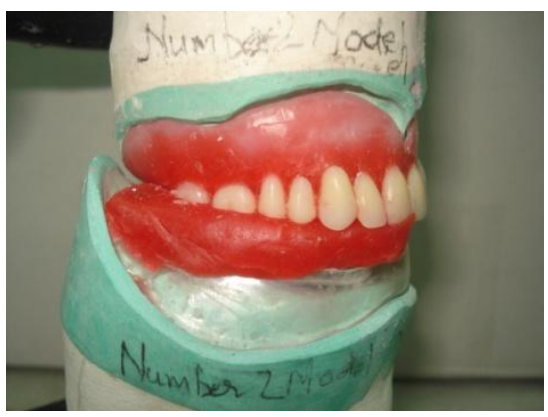

Figure 5: Wax squash bite made in modelling wax

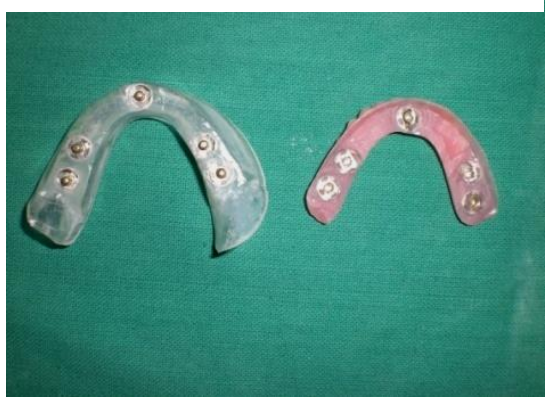

Figure 8: Lower part (Clear acrylic) \& Upper part (Pink acrylic)

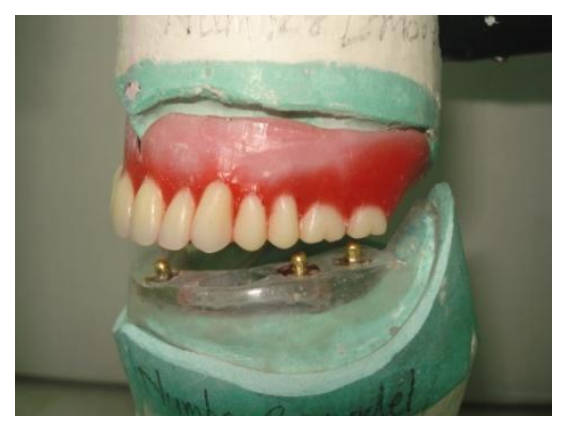

Figure 3: Wax Upper denture against clear acrylic base

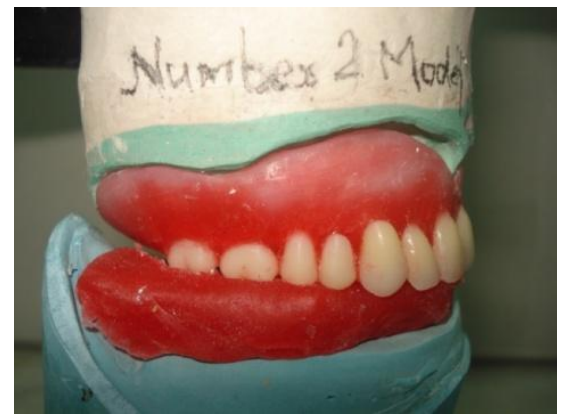

Figure 6: Die-Stone duplicate placed in position

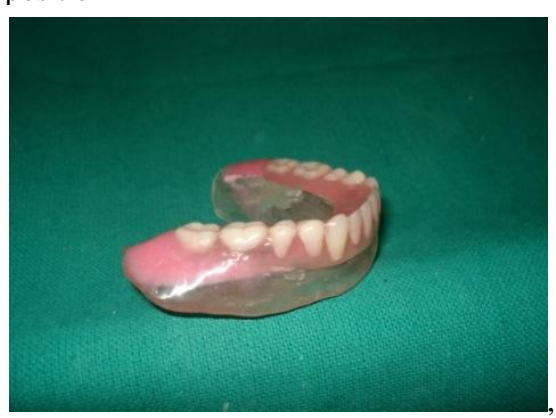

Figure 9: Final lower denture 
Denture issue and reservoir placement:- The denture, still with no reservoirs, was now issued to the patient and worn for a time to allow the patient to adjust and complete any minor adjustments. Once this was achieved, reservoirs were cut into the clear, acrylic base of the denture. Because a clear acrylic was used for the base section, the extent of the reservoirs could be clearly visualized (Fig.10). The reservoirs were made as large as possible while maintaining sufficient thickness of the denture walls for strength. A minimum thickness of $2 \mathrm{~mm}$ was maintained for the reservoir walls. Once the reservoirs were placed, a $0.5 \mathrm{~mm}$ diameter rose bur was used to drill a drainage hole from the inferior aspect of the lingual flange of the denture into the reservoirs. Drainage was tested by filling the reservoirs with water, placing the denture on a paper towel and checking that capillary action slowly drained the chambers (Fig.11). ${ }^{13}$

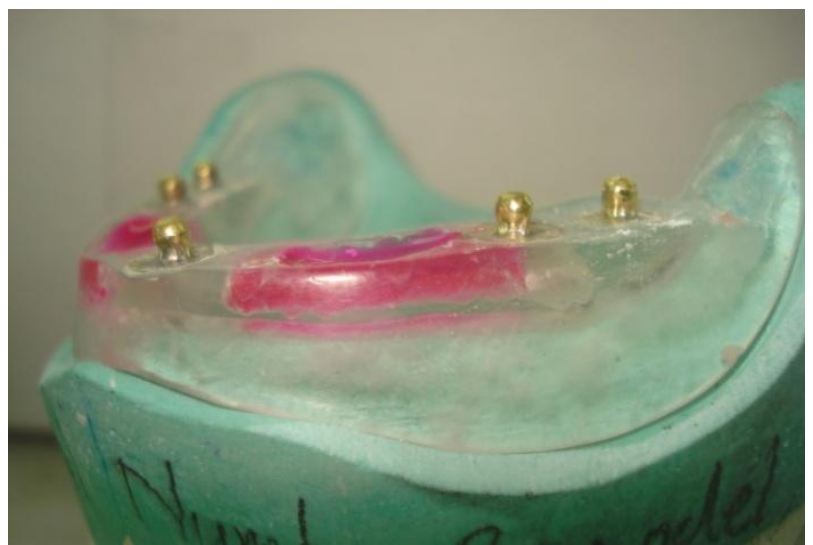

Figure 10: Coloured liquid filled to show the reservoir

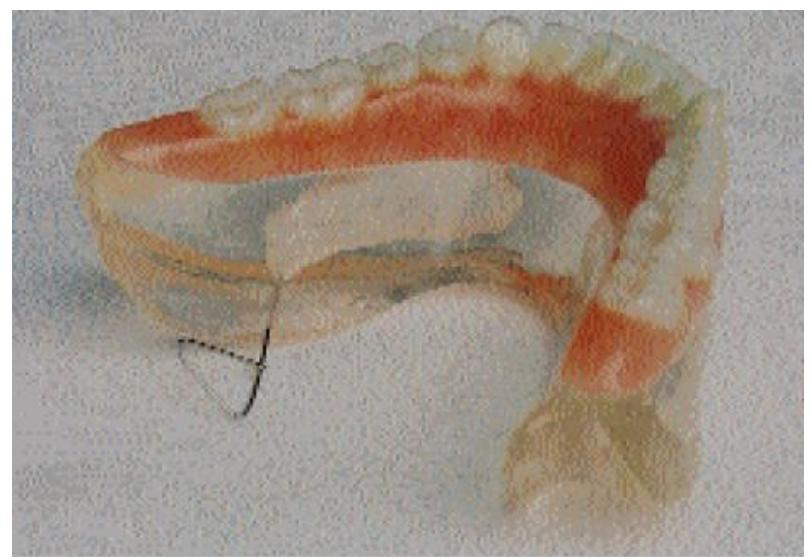

Figure 11: Drainage of reservoir liquid

\section{CONCLUSION}

Mechanism of retention is a highly complex one, under the control of numerous factors. Chief among them are the forces related to the wetting of the denture and the surface tension, adhesive and cohesive characteristics of the saliva, without which denture wearing becomes a painful process. Thus saliva plays a profound role in the maintenance of oral health in the denture wearing patient. Since the quality \& quantity of saliva have an important role in the success of complete dentures, the patients with hyposalivation need to be treated to prevent adverse effects on the oral mucosa.

\section{REFERENCES}

1. Valdez H.I, Fox C.P, Diagnosis and Management of Salivary Dysfunction, Critical Reviews in Oral Biology and Medicine 1993;4(3/4):271-277

2. Silvestre J.F et al, Clinical evalution of a new artificial saliva in spray form for patients with dry mouth , Med Oral Patol Cir Bucal, 2009 Jan;14(1):E8-E11

3. Blahova $\mathrm{Z}$, Neuman $\mathrm{M}$, Physical factors in retention of complete dentures. J Prosthet Dent 1971;25:230-35

4. Nakamoto R.Y, Use of a saliva substitute in postradiation xerostomia. J Prosthet Dent 1979;42:539-42

5. Lindstrom R.L et al, Physical-chemical aspects of denture stability: A review of the literature, J Prosthet Dent 1979;42:371-75

6. Vergo T.J, Kadish S.P, Dentures as artificial saliva reservoirs in the irradiated edentulous cancer patient with xerostomia: A pilot studv, Journal of Oral Surgery 1981;51:229-33

7. Toljanic A.J, Zucuskie G.D, Use of a palatal reservoir in denture patients with xerostomia. J Prosthet Dent 1984;52:540-44

8. Edgerton $\mathrm{M}$ et al, Saliva: A significant factor in removable prosthodontic treatment. J Prosthet Dent 1987;57:57-66

9. Ferguson M.M, Barker M.J, Saliva substitutes in the management of salivary gland dysfunction. Advanced Drug Delivery Reviews. 1994;13:151-159

10. Sinclair G.F et al, New design for an artificial saliva reservoir for the mandibular complete denture. J Prosthet Dent 1996;75:276-80

11. Diaz-Arnold A.M, Marek C.A, The impact of saliva on patient care: A literature review. J Prosthet Dent 2002;88:337-43

12. Chambers M.S et al, Salivary flow rates measured during radiation therapy in head and neck cancer patients: A pilot study assessing salivary sediment formation. J Prosthet Dent 2008;100:142-46

13. Mendoza A.R, Tomlinson M.J, The split denture: A new technique for artificial saliva reservoirs in mandibular dentures, Australian Dental Journal 2003;48:190-194

14. Guyton and Hall, Text book of Medical Physiology, 11 th Ed, Philadelphia, Pennsylvania, Elsevier Saunders, 791-807.

15. Ganong W.F, Review of Medical Physiology, 21 st Ed, San Fransisco, Mc-Graw Hill. 
16. Porter S.R et al, An update of the etiology and management of xerostomia. Journal of Oral Surgery,Oral medicine,Oral pathology 2004;97:28-46

17. Humphrey P.S, Williamson T.R, A review of saliva: Normal composition, flow and function. J Prosthet Dent 2001;85:162-9
18. Atkinson C.J, Grisius M, Massey W, Salivary Hypofunction and Xerostomia: Diagnosis and Treatment. Dent Clin N Am 2005;49:309-26

19. Turner $M$ et al, Hyposalivation, xerostomia and the complete denture A systematic review. J Am Dent Assoc 2008;139:146-150

\section{Source of Support: Nil, Confilict of Interst: None Declared}

